\title{
A COMPACT SUB-ANGSTROM X-RAY SOURCE FOR PROTEIN CRYSTALLOGRAPHY, NANO-TECHNOLOGY AND CORONARY ANGIOGRAPHY
}

\author{
David Cline, Alper Garrenț, and James Kolonko \\ Center for Advanced Accelerators . Physics Department \\ University of California. Los Angeles, California 90024-1547
}

\begin{abstract}
We describe the scientific motivation and a schematic design of a very compact superconducting $1.5 \mathrm{GeV} \mathrm{X}$-ray storage ring. Prototype tests of the 8 Tesla magnets are the key factor in the realization of this machine.
\end{abstract}

\section{INTRODUCTION}

We believe there will be a strong commercial interest in a very hard X-ray source that is compact enough for hospitals and industrial laboratories. There are three potential applications:

(1) Protein Crystallography ${ }^{1}$ :

There is on going interest in drug designs based on an X-ray study of a crystallized virus, etc., and $\mathrm{X}$-rays in the range $8-15 \mathrm{KeV}$ are needed.

(2) Coronary Angiography ${ }^{2}$ :

It has now been demonstrated that $\mathrm{X}$-ray snap shots of the human heart can detect the build-up of dangerous substances in the arteries. For this use the $\mathrm{X}$-ray energy should be $\sim 33 \mathrm{KeV}$.

(3) Nano-Technology:

$\mathrm{X}$-ray lithography hard X-rays will be crucial for future micro-technologies and may be important for future generation silicon chip development. The design presented here follows a previous study of a very compact $700 \mathrm{MeV}$ light source ${ }^{3}$.

For the applications listed above we have carried out a preliminary study of the most compact storage ring that will still have fairly good beam properties. The kev component is a very powerful 8 Tesla superconducting bending magnet.

\section{OUTLINE OF THE MACHINE}

The ring has a racetrack shape, shown schematically in Fig. 1. It has reflection symmetry about a vertical line through the center of the figure. It consists of two arcs and two straight sections: the straight sections have equal lengths but different beam optics. The magnet layout and orbit functions are shown in Fig. 2. The origin is in the center of the insertion-device region. Quadrupoles are represented by rectangles shown above or below the axis, according to whether they are horizontally focussing or defocussing, respectively. Dipoles are shown as rectangles centered on the axis.

Each arc consists of three cells with the following cell structure:

$$
Q F \quad D \quad B \quad D \quad Q F
$$

where $\mathrm{QF}$ is half of an F-quadrupole, $\mathrm{D}$ is a drift space, and $\mathrm{B}$ is a rectangular dipole. The cell closest to the insertion straight section in each arc is missing its first two elements. The cell at the center of each arc contains, in addition, two horizontally focussing sextupoles, SF, which are combined with the QF quadrupoles, and two vertically focussing sextupoles, SD, at the centers of the drift spaces, D.

† Also Lawrence Berkeley Laboratory, Accelerator \& Fusion Division, 1 Cyclotron Rd, Berkeley, CA 94720 


\section{THE 8 TESLA MAGNETS}

The key to the success of any compact light source is the design and construction of the appropriate superconducting magnet. Several projects have failed (COSY, XLS) due to a failure to produce an adequate magnet.

The key to the development of this superconducting X-ray source is to construct and test some of the components ${ }^{4}$. This is especially necessary for the novel superconducting bend magnet. Construction of such a device will also illuminate problems with short, very high field superconducting bend magnets (multipole terms, edge effects). This will advance the state of the art for compact light sources as well as allow us to understand the overall scaling principles for higher energy machines.

\section{TESTS OF THE 8 TESLA MAGNET USING THE XLS STORAGE RING}

The major problem to date in the development of a high quality compact X-ray source is the superconducting magnet performance. We strongly suggest an aggressive program to develop a prototype followed by a careful study of the magnet(s) in a storage ring to test the crucial tolerances of the magnet(s). Fig. 3 shows a possible method to test the 8 Tesla magnets using the $200 \mathrm{MeV}$ XLS Storage Ring. This technique would be very sensitive to the fringe fields. It is essential that the magnets be tested with a stored $e^{-}$beam!

\begin{tabular}{|l|c|}
\hline \multicolumn{2}{|c|}{ Table 1: Parameters for the Hard X-ray Source } \\
\hline Electron Energy $(\mathrm{GeV})$ & 1.5 \\
$\gamma$ & 3914 \\
Circumference $(\mathrm{m})$ & 22.62 \\
\hline Tune $\nu_{x}$ & 2.83 \\
Tune $\nu_{y}$ & 3.30 \\
Horizontal Emittance, unnormalized $(\mathrm{m}-\mathrm{rad})$ & $2.326 \times 10^{-6}$ \\
Vertical Emittance, fully coupled $(\mathrm{m}-\mathrm{rad})$ & $1.163 \times 10^{-6}$ \\
\hline Horizontal, $\beta_{\max }(\mathrm{m})$ & 5.4 \\
Horizontal, $\beta_{\min }(\mathrm{m})$ & 0.63 \\
Vertical, $\beta_{\max }(\mathrm{m})$ & 6.2 \\
Vertical, $\beta_{\min }(\mathrm{m})$ & 0.09 \\
\hline RF Voltage $(\mathrm{kV})$ & 2000 \\
FR Frequencey $(\mathrm{MHz})$ & 499 \\
Momentum Compaction & 0.0985 \\
Bunch Length, $\sigma_{1}(\mathrm{~cm})$ & 2.2 \\
\hline
\end{tabular}




\section{COMPARISON WITH OTHER HARD X-RAY LIGHT SOURCES}

We have presented the preliminary design of a very compact hard X-ray source that is designed for industrial, medical and biotechnological uses. In Table 2 we compare the size of our machine with that of other possible hard X-ray machines. Note that the small size and the strong and efficient X-ray source emission at the $60^{\circ}$ dipole bends make this machine a very effective X-ray source.

The most important components of this storage ring are the 8 Tesla superconducting magnets. We are working with the General Dynamics and LBL goups to propose the construction of a prototype magnet in the near future.

\begin{tabular}{|c|c|c|c|c|c|}
\hline & GROUP & $E_{\text {beam }}$ & $\mathrm{E}_{\text {Critical }}^{\mathrm{X}-\mathrm{ray}}$ & No. Dipoles & Circumference \\
\hline (I) & $\begin{array}{c}\text { Maxwell }^{5} \\
(\text { Model } 2.5-100)\end{array}$ & $2.5 \mathrm{GeV}$ & $6.2 \mathrm{KeV}$ & 12 & $77 \mathrm{~m}$ \\
\hline (II) & $\begin{array}{c}\text { ROSY } \\
\text { (Germany) }\end{array}$ & $3 \mathrm{GeV}$ & $8.4 \mathrm{KeV}$ & 20 & $148.1 \mathrm{~m}$ \\
\hline (III) & $\begin{array}{c}\text { Akashi, Tech } 2 \\
\text { Kawasaki Heavy I }\end{array}$ & $\begin{array}{l}1.75 \mathrm{GeV} \\
\text { Ist. (Japa }\end{array}$ & $?$ & $?$ & $60 \mathrm{~m}$ \\
\hline (IV) & $\begin{array}{c}\text { UCLA } \\
\text { General Dynamics }\end{array}$ & $\begin{array}{l}1.5 \mathrm{GeV} \\
\text { LBL }\end{array}$ & $\begin{array}{c}\sim 12 \mathrm{KeV} \\
(8 \mathrm{~T})\end{array}$ & 6 & $22 \mathrm{~m}$ \\
\hline
\end{tabular}

\section{REFERENCES}

1. Private communication, W. Smith, Agouron Corp, San Diego.

2. See for example the report of dedicated Coronary Angiography Ring by the Japanese Group and reported tothe Washington Particle Accelerator Conference, Y. Oku, et al (1993).

3. D. Cline, et al, Design of a Compact Superconducting X-ray Source, UCLA-CAA-0084-2/92; we discuss the other important issues such as the vacuum pipe system in this report.

4. Private communication, M. Green (LBL), D. Madura and E. Leung (General Dynamics).

5. Data sheet DS-39, Maxwell, Brobeck Division, Richmond, CA.

6. The Sychrotron Light Source ROSY, D. Einfield, et al, Proceedings of the 1993 PAC Conference, Washington DC. 


\section{UCLA I.5 GEV LIGHT SOURCE}

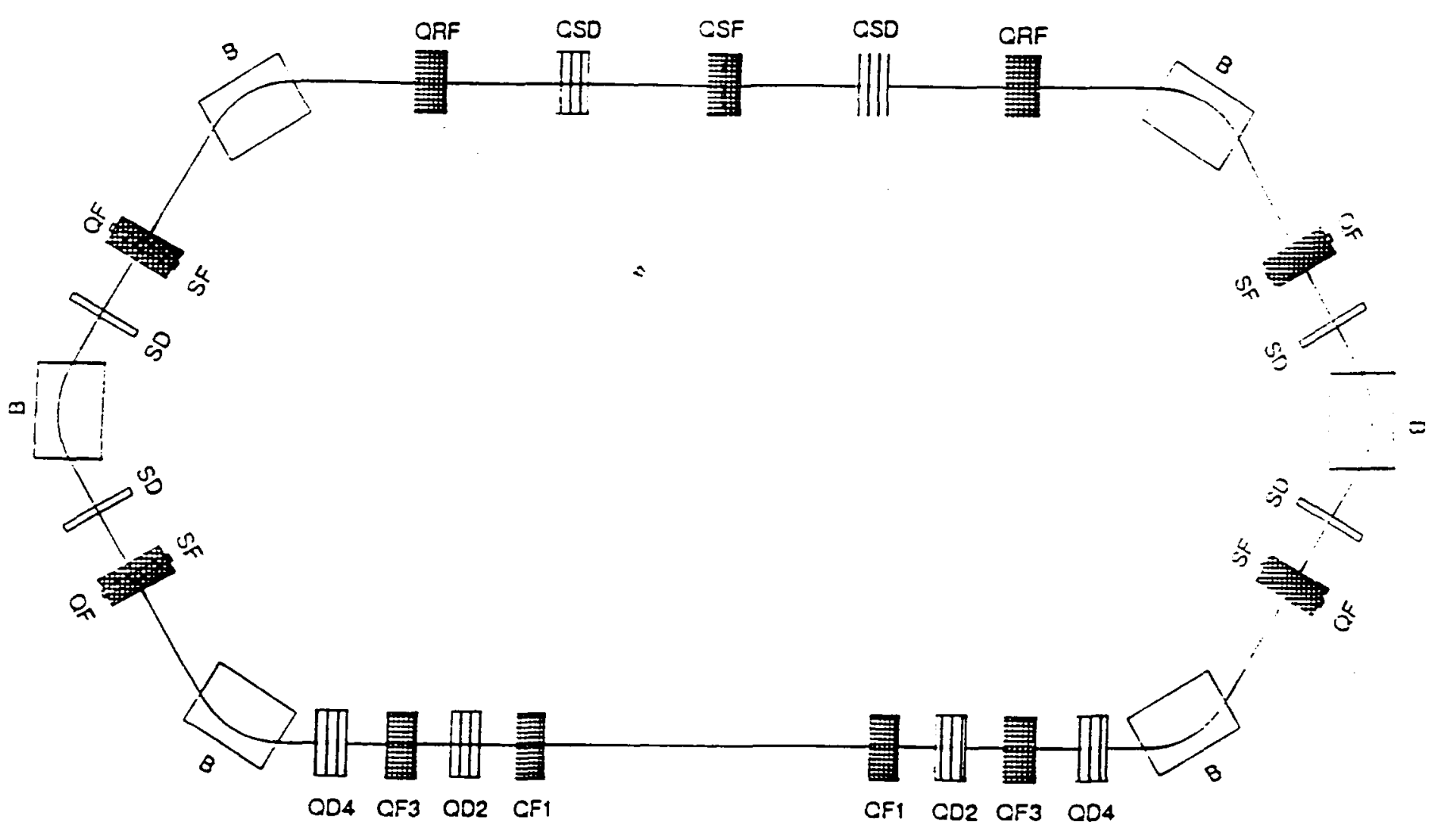

Fig. 1: A very compact hard X-ray source using an 8 Tesla superconducting magnet. 


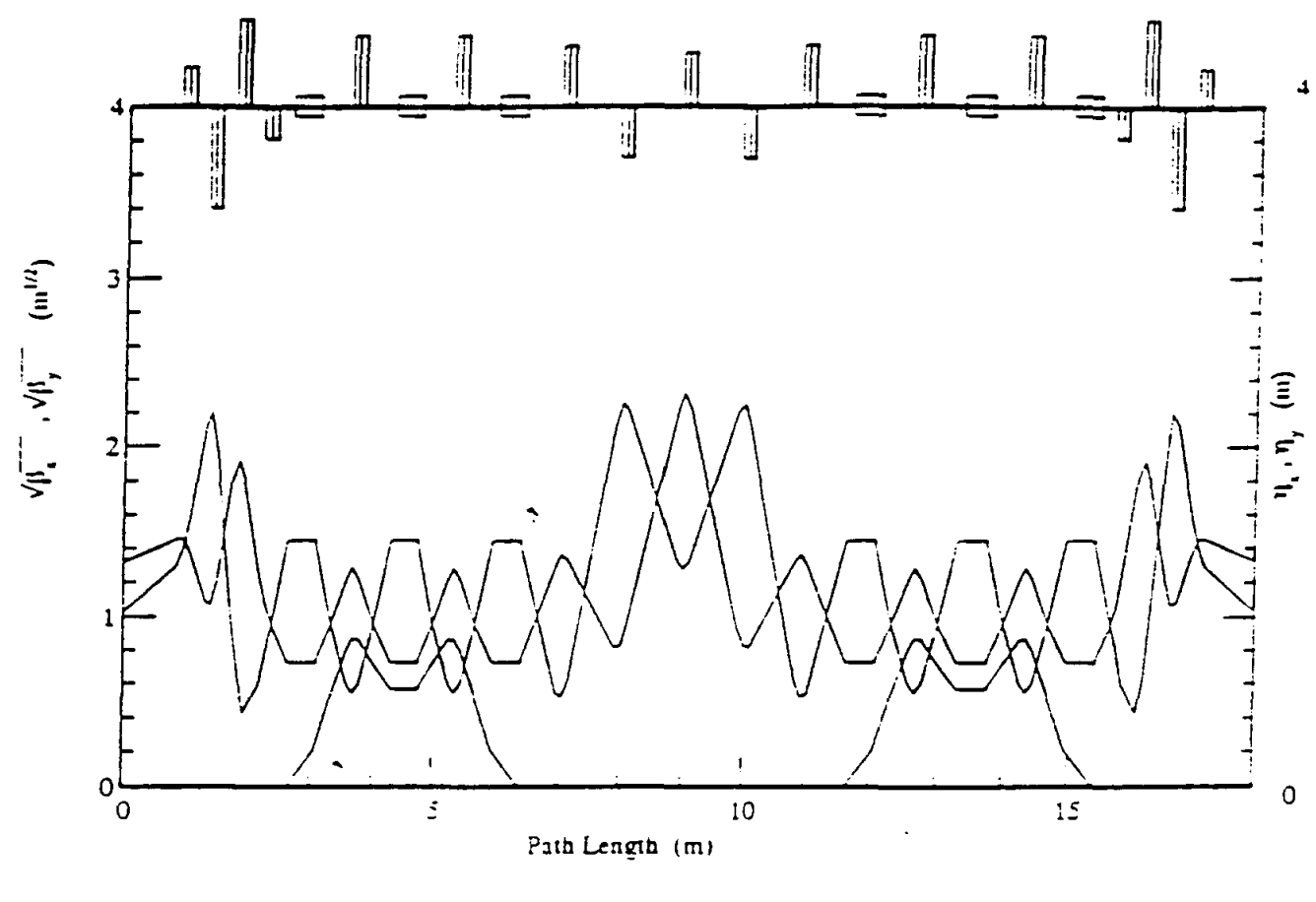

Twe Mar 5 :5:4::2?: 2992

Fig. 2: Lattice parameters for the light source. The insertion device region is in the center of the straight section shown at the ends of the figure; the injection system is in the straight section shown in the center of the figure. 


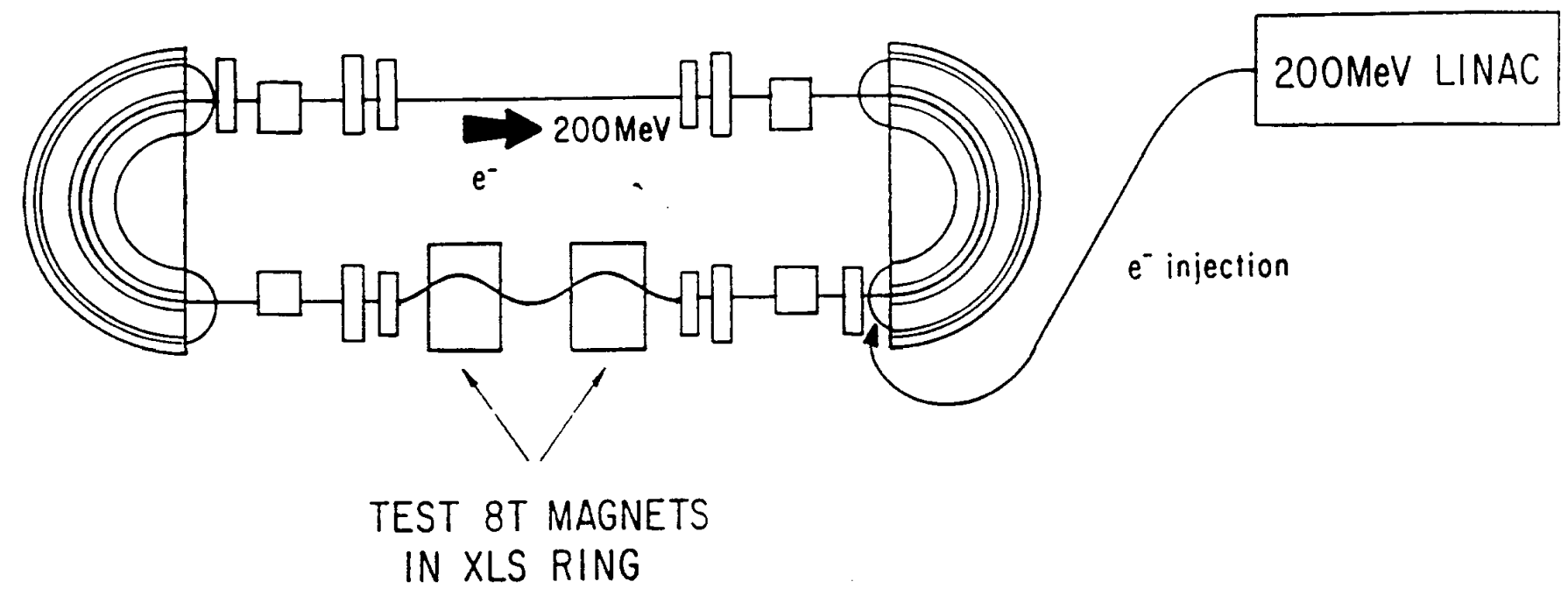

Fig. 3: The schematic showing the 8 Tesla magnets in the XLS Ring. 